\title{
EFFECTS OF DIETARY SUPPLEMENTATION OF ALFALFA (MEDICAGO SATIVA) FIBRE ON THE BLOOD BIOCHEMISTRY, NITROGEN METABOLISM, AND INTESTINAL MORPHOMETRY IN WEANING PIGLETS
}

\author{
ADAMS, S. ${ }^{1}-$ KonG, X. ${ }^{1}-$ CHE, D. $.^{1,2,3^{*}}-$ QIN, G. ${ }^{1,2,3}-$ JIANG, H. ${ }^{1,2,3 *}$ \\ ${ }^{I}$ College of Animal Science and Technology, Jilin Agricultural University \\ Changchun 130118, China \\ ${ }^{2}$ Key Laboratory of Animal Production, Product Quality and Security, Ministry of Education \\ Changchun 130118, China \\ ${ }^{3}$ Jilin Provincial Key Laboratory of Animal Nutrition and Feed Science \\ Changchun 130118, China \\ *Corresponding authors \\ H. Jiang-e-mail: hljiang@jlau.edu.cn; phone: +86-186-0446-5676; fax: +86-186-0446-5676 \\ D. Che-e-mail: chedongsheng@jlau.edu.cn; phone: +86-136-4431-9554 \\ (Received $24^{\text {th }}$ Nov 2018; accepted $11^{\text {th }}$ Jan 2019)
}

\begin{abstract}
Alfalfa (Medicago sativa) is a high-yielding perennial legume, cultivated worldwide with rich nutritional characteristics, and active compounds. A total of 48 crossbred (Duroc $\times$ Landrace $\times$ Yorkshire) piglets weaned at 28 days old with an average body weight of $8.42 \pm 1.88 \mathrm{~kg}$ was used in this study. The results indicated that the supplementation of $6-12 \%$ alfalfa fibre significantly $(\mathrm{P}<0.05)$ increased the growth performance. The digestibility of crude protein $(\mathrm{CP})$ increased at higher dietary alfalfa fibre concentrations. The crude fibre (CF) and dry matter (DM) levels increased first and then decrease at higher alfalfa fibre concentration. The inclusion of alfalfa fibre increased the nitrogen $(\mathrm{N})$ metabolism through increasing $\mathrm{N}$ digestibility and utilization and decrease fecal and urinary $\mathrm{N}$ content. In addition, the supplementation of alfalfa fibre increased the albumin, globulins, and total protein levels. However, dietary alfalfa fibre decreased blood glucose levels, cholesterol, triglyceride, aspartate aminotransferase, and alanine aminotransferase. There was a significant increase in the villus height $(\mathrm{VH})$, crypt depth (CD), and villus height to crypt depth (VH-CD) ratio after introducing alfalfa fibre in the diet. Therefore, the inclusion of alfalfa fibre to piglet's diet is significant in improving the production performance and health in piglets.
\end{abstract}

Keywords: Medicago sativa, gastrointestinal tract, digestibility, performance, pigs

\section{Introduction}

The increasing consumer demand for organic food products such as natural pork and the emergence of antibiotic resistance among many pathogenic microorganisms has necessitated the search for an alternative approach to healthy production systems and the control of microbial infection in pigs (Che et al., 2018; Adams et al., 2019a, 2019b). The use of different plant base components such as dietary fibre, prebiotics, and polysaccharide seem to be promising (Griggs and Jacob, 2005; Che et al., 2018; Adams et al., 2018a). However, there are differences in the nutritional composition of different fibre containing feedstuffs (Jarrett and Ashworth, 2018). Dietary fibre can be defined as the indigestible portion of food obtained from plants which form the main component of many animals (pig) diet (Jarrett and Ashworth, 2018). Dietary fibre influences the functions of the gastrointestinal tract and the health of both animals and human (Bikker 
et al., 2006; Adams et al., 2018b). The consumption of high dietary fibre decreases the bioavailability of some key nutritional components such as some minerals and vitamins (Adams et al., 2018b) and may influence the rate of digestion of food substances and energy metabolism (Adams et al., 2018c). The intake of high-fibre diet can also increase the activities of the gut microbial composition (Varel 1987; Metzler and Mosenthin 2008), hence producing short-chain fatty acid that accounts for 10-30\% of the total energy requirement of animals (Christensen et al., 1999).

Alfalfa is a high-yielding perennial legume which is cultivated worldwide with rich nutritional characteristics and active compounds (Yu et al., 2014; Chen, et al., 2016). Alfalfa fibre is primarily composed of insoluble dietary fibre, such as cellulose, lignin, and xylans, which represents more than $90 \%$ of the total dietary fibre composition of alfalfa (Bach Knudsen, 1997; Chen et al., 2013a). Alfalfa meal is high in protein and minerals as well as vitamins (Ensminger, 1992). For example, alfalfa contains vitamins such as: A, B1, B2, B6, B12, C, D, E, K, Niacin, Panthothanic acid, Inocitole, Biotin, and Folic acid with minerals such as: Boron, Calcium, Chlorine, Copper, Cobalt, Iron, Magnesium, Manganese, Molybdenum, Phosphorus, Potassium, Sodium, and Sulphur, as well as, well balanced amino acids, rich in carotenoids, and xanthophylls (Sen et al., 1998; Ponte et al., 2004; Jiang et al., 2012). Reportedly, alfalfa contains $17.5 \%$ CP, $24.1 \% \mathrm{CF}$, and $1,200 \mathrm{kcal} / \mathrm{kg}$ metabolizable energy (National Research Council, 1994). Wang et al. (2018) indicated that the growth of pigs on alfalfa pastures produces natural and good quality pork, which is currently gaining more attention in Europe and North America. Interestingly, for the production of better quality pork, alfalfa is used as a fresh fodder in some traditional style pig production systems in China (Wang et al., 2018). Alfalfa fibre is a high-quality protein feed hence increasing its supplementation may improve the nutritional requirement of pigs and improve the growth of piglets. Few studies reported that the supplementation of natural compounds such as flavonoids extracted from alfalfa had insignificant estrogenic impacts, which may increase the production performance, enhance antioxidant, anti-stress induction, and eradicate free radicals from animals (Xie, 2001).

Weaning in piglets is a harsh condition that is mostly associated with a growth disorder and health effects. Weaning piglets are associated with less feed consumption and low nutrient metabolism due to the immature digestive systems, stress as a result of the separation from the dam and littermates, and the sudden change from the easily digestible sow's milk to a less digestible solid feed (Chen et al., 2017). These piglets have limited susceptibility to diseases and infections from enteric bacteria accompanied with frequent diarrhea, stunted growth, low nutrient utilization efficiency, and even mortality (Kick et al., 2012; Che et al., 2018). The supplementation of alfalfa in the diet of pigs has increased in recent years due to the beneficial effects of dietary alfalfa consumption. Dietary alfalfa supplementation increased the short-chain fatty acid concentration in fecal samples of growing pigs (Chen et al., 2013a). Also, alfalfa increased the microbial activities and butyrate levels in the hindgut of the intestinal tract of pigs (Wang et al., 2018).

Therefore, we hypothesize that supplementing alfalfa fibre in the diet of weaning piglets may increase the production performance, blood biochemical composition, and improve the intestinal development and health. Hence, the aim of this study was to investigate the effects of dietary alfalfa fibre supplementation on the growth performance, nutrient digestibility, $\mathrm{N}$ metabolism, blood biochemical composition, and intestinal development in piglets. 


\section{Materials and methods}

\section{Experimental site and location}

The animal feeding experiment was conducted from 27th June to 21st August, 2017, involving 7 days of a pre-feeding period and a 48 days' formal test period at the animal breeding station of Jilin Agricultural University, located in Changchun city in the Jilin Province in the People's Republic of China. Jilin is found on latitude $43^{\circ} 42^{\prime} \mathrm{N}$ and longitude $126^{\circ} 12^{\prime} \mathrm{E}$, and Changchun is on latitude $43^{\circ} 88^{\prime} \mathrm{N}$ and longitude $125^{\circ} 35^{\prime} \mathrm{E}$. The annual rainfall ranges between 350-1000 mm (March-August) and the dry season between September - February. Winter ranges between November - March with temperatures between $-8{ }^{\circ} \mathrm{C}\left(17^{\circ} \mathrm{F}\right)--20^{\circ} \mathrm{C}\left(-4.6^{\circ} \mathrm{F}\right)$ and summer temperatures between $16^{\circ} \mathrm{C}\left(61.4^{\circ} \mathrm{F}\right)$ and $28^{\circ} \mathrm{C}\left(81.2^{\circ} \mathrm{F}\right)$ around May-July.

\section{Sample preparation}

The alfalfa was obtained from the STONE WINGSII, LLC. \& SW Forage, LLC, USA. The alfalfa fibre was extracted by crushing it through a $5 \mathrm{~mm}$ sieve and the extract was stored in a closed vessel at room temperature prior to being incorporated into the trial diets.

\section{Experimental animals, design and feeding management}

A total of 48 crossbred (Duroc $\times$ Landrace $\times$ Yorkshire) piglets weaned at 28 days old with an average body weight of $8.42 \pm 1.88 \mathrm{~kg}$ were used in this study (Fig. 1). The trials were divided into four treatment groups according to a completely randomized design with each treatment group comprised of four replicates and each replicate contains three piglets. The animals were housed in pens $(1.8 \times 1.2 \mathrm{~m})$ with a concrete slatted floor each pen contained three piglets. The pens were cleaned on a daily basis to prevent disease outbreak in piglets. The animals were allowed to acclimatize to the diets for a week prior to the beginning of the experiment and lasted for 48 days. Four experimental diets containing $0.00 \%$ alfalfa fibre (control group, M0), $6.00 \%$ alfalfa fibre (M6), $12.00 \%$ alfalfa fibre (M12), and $18.00 \%$ alfalfa fibre (M18) were formulated according to the requirements of the National Research Council (2012). The diets contain soybean meal and cracked corn as the main sources of protein and energy respectively (Table 1). The piglets were fed twice a day at 08: 30 am and 05:30 pm and had ad libitum access to clean drinking water. Feed intake and leftover were recorded daily in the morning for each animal.

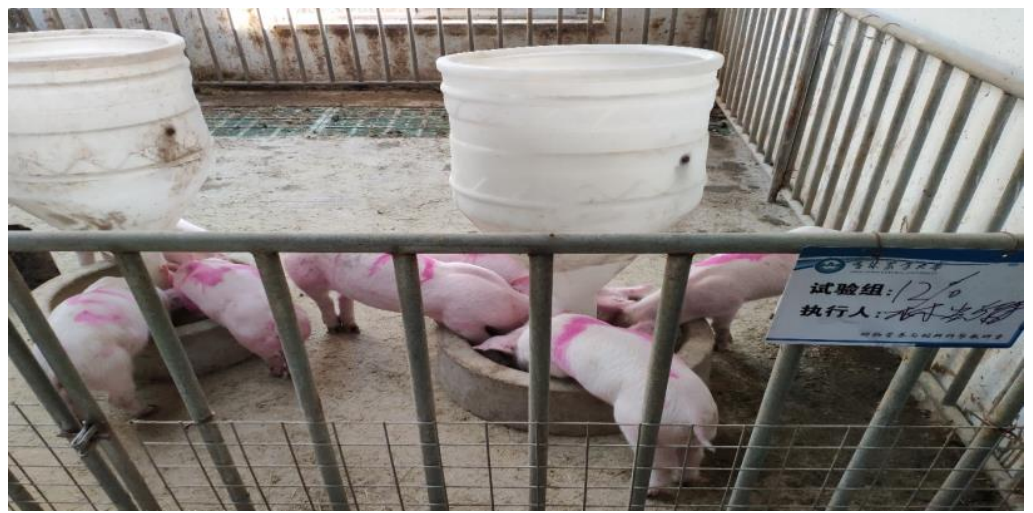

Figure 1. Photo of experimental pigs 
Table 1. Composition and nutritional levels of the basal diets ( $\mathrm{kg}^{-1}$ as fed)

\begin{tabular}{c|c|c|c|c}
\hline Items & M0 & M6 & M12 & M18 \\
\hline Corn & 53.50 & 50.29 & 45.00 & 40.00 \\
Soybean meal & 28.00 & 26.32 & 24.64 & 22.00 \\
Alfalfa fibre & 0.00 & 6.00 & 12.00 & 18.00 \\
Fish meal & 3.00 & 2.82 & 3.69 & 5.10 \\
Whey powder & 9.00 & 5.50 & 5.50 & 5.00 \\
Wheat bran & 1.00 & 1.00 & 1.00 & 1.00 \\
Limestone powder & 1.30 & 1.22 & 1.14 & 0.90 \\
Calcium hydroxide & 0.80 & 0.75 & 0.70 & 0.66 \\
Wheat middlings feed & 2.00 & 1.88 & 1.76 & 1.64 \\
Rapeseed oil & 0.60 & 1.50 & 3.56 & 4.70 \\
Premix & 1.00 & 1.00 & 1.00 & 1.00 \\
\hline Nutritional level & & & & \\
Digestive energy Mcal/kg & 3.41 & 3.33 & 3.31 & 3.26 \\
CP & 20.10 & 20.02 & 20.06 & 20.27 \\
CF & 2.83 & 4.21 & 5.55 & 6.84 \\
Lysine\% & 1.14 & 1.12 & 1.12 & 1.13 \\
Methionine \% + cysteine \% & 0.69 & 0.67 & 0.65 & 0.65 \\
Threonine\% & 0.81 & 0.81 & 0.81 & 0.82 \\
Isoleucine\% & 0.87 & 0.86 & 0.86 & 0.87 \\
Leucine\% & 1.72 & 1.68 & 1.65 & 1.64 \\
Proline \% & 0.92 & 0.92 & 0.92 & 0.91 \\
Phenylalanine\% & 0.99 & 0.98 & 0.98 & 0.99 \\
Tryptophan\% & 0.30 & 0.32 & 0.34 & 0.38 \\
Calcium to phosphorus ratio & $2: 1$ & $2: 1$ & $2: 1$ & 2.1 \\
\hline Prenix is avalab per kg & VA & & & \\
\hline
\end{tabular}

Premix is available per kg of feed: VA 130-396 KIU, VD2 30-124 KIU, VE $400 \mathrm{mg}$, VK2 40-150 mg, VB1 $25 \mathrm{mg}$, VB2 $75 \mathrm{mg}$, Cu 1500-7500 mg, Fe 1500-7500 kg, Zn 1500-3700 kg, Mn 400-3700 kg, moisture 9\%, sodium chloride $\mathrm{NaCl} 6-14 \%$, total phosphorus P 2\%, lysine Lys $1.3 \%$, Ca 10-20\%, Phytase 12500U. M0: $0.00 \%$ alfalfa diet, M6: $6.00 \%$ alfalfa diet, M12: $12.00 \%$ alfalfa diet, M18: $18.00 \%$ alfalfa diet

\section{Sample collection}

The fecal samples were collected continuously from 08:30 am to 05:30 pm on day 40 to day 45 of the trial period for the determination of nutrient digestibility. The urine was collected within the same time frame as the fecal samples. After each collection, $10 \%$ hydrochloric acid was added for fixation of fecal and urine $\mathrm{N}$. The fecal samples were thawed and homogenized within the group, weighed, and dried at $55{ }^{\circ} \mathrm{C}$ for $72 \mathrm{~h}$. The dry fecal samples were ground through a $1-\mathrm{mm}$ screen sieve and stored in $-20{ }^{\circ} \mathrm{C}$ until chemical analysis. The experimental diets were sampled and stored in $-20{ }^{\circ} \mathrm{C}$ for the $\mathrm{DM}, \mathrm{CP}$, and $\mathrm{CF}$ analysis. Blood samples were collected from the precaval vein by venepuncture at 8:30 am on day 47 after $12 \mathrm{~h}$ of fasting and centrifuged at $1500 \times \mathrm{g}$ for $30 \mathrm{~min}$ at $4{ }^{\circ} \mathrm{C}$. The serum samples were then isolated and frozen at $-20{ }^{\circ} \mathrm{C}$ until analysis. At the end of the experiment on day 48, all the pigs were electrically stunned and killed by exsanguination. The abdominal cavity was immediately opened to remove the duodenum, jejunum, and ileum. The middle part $(5 \mathrm{~cm})$ of the duodenum, jejunum, and ileum was collected and fixed in $10 \%$ formalin solution for intestinal morphological 
analysis. The sample of mucosa scraped obtain from the duodenum, jejunum, and ileum was immediately frozen in liquid $\mathrm{N}$, then stored in $-80{ }^{\circ} \mathrm{C}$ until biochemical analysis (Wu et al., 2018).

\section{Determination of growth performance}

The piglets were weighed early in the morning prior to feeding on the first and last days of the feeding trials. The average daily feed intake (ADFI) was determined by estimating the total feed consumption per day. The average daily gain (ADG) was calculated by subtracting the initial body weight from the final body weight and divided by the days of the experiment. Feed conversion ratio (FCR) was determined by dividing the feed intake by the body weight gain.

\section{Determination of nutrient digestion}

The feed and fecal samples were analyzed for CP, CF, and DM digestibility according to the procedures described by (Hassanat et al., 2017; Che et al., 2018). Briefly, the DM content was estimated by drying feed and fecal samples in a vacuum oven at $100{ }^{\circ} \mathrm{C}$ overnight (AOAC, 1990; method 934.01). The $\mathrm{CP}(\mathrm{N} \times 6.25)$ was estimated using the macro-Kjeldahl procedure (AOAC, 1990; method 990.03) and the $\mathrm{CF}$ was determined using the procedures adapted for use in an Ankom200 Fiber Analyzer (Ankom Technology Corp., Fairport, NY).

\section{Determination of nitrogen metabolism}

The $\mathrm{N}$ content of all the samples was analyzed using the KjeltecTM 8400 automated Kjeldahl analyzer (PT Haes Brothers, Laboratory \& Scientific Equipment). The following formula (Eqs. 1-6) was used to estimate the $\mathrm{N}$ metabolism in the diet, urine, and fecal samples.

$$
\begin{gathered}
\text { The } \mathrm{N} \text { intake }(\mathrm{g})=\frac{\text { daily feed intake } \times C P \% \text { in the diet } \times 15.67}{100} \\
\mathrm{~N} \text { in feces }(\mathrm{g})=\text { average daily fecal } D M(g) \times \text { fecal } N(\%) \\
\mathrm{N} \text { in urine }(\mathrm{g})=\text { average daily urine }(\mathrm{mL}) \times N \text { in urine }(\%) \\
\mathrm{N} \text { deposition }(\mathrm{g})=N \text { intake }(\mathrm{g})-\text { fecal } N(\mathrm{~g})-N \text { in urine } \\
\text { Apparent } \mathrm{N} \text { digestibility }(\%)=\frac{N \text { intake }-f \text { ecal } N}{N \text { intake }} \times 100 \\
\mathrm{~N} \text { utilisation }=\frac{N \text { intake }-f \text { fecal } N-N \text { in urine }}{N \text { intake }} \times 100
\end{gathered}
$$

\section{Determination of blood biochemical composition of piglets}

The albumin, globulin, blood glucose, urea N, triglyceride, cholesterol, aspartate aminotransferase, and alanine aminotransferase in the serum were determined by an automatic blood analyzer (7020 Clinical Analyzer, https://www.hitachihightech.com/global/) according to the manufacturer's instruction. 


\section{Piglet's intestinal morphological analysis}

The intestinal segments such as the duodenum, jejunum, and the ileum was analyzed for the $\mathrm{VH}, \mathrm{CD}$, and $\mathrm{VH}-\mathrm{CD}$ ratio using paraffin sectioning and the procedures described by $\mathrm{Wu}$ et al. (2018). Briefly, the paraffin sections were made by 1 . Flushing: The trimmed tissue samples were wrapped in gauze and rinsed under running water for 24 h. 2. Dehydration: The washed tissue samples were taken out and placed on alcohol for dehydration. The concentration of alcohol as a dehydrating agent is gradually increased from $30 \%$ so that the tissue sample is gradually dehydrated, and finally dehydrated thoroughly with absolute ethanol. 3. Transparent: The dehydrated tissue sample was soaked in a solution prepared with alcohol and xylene 1:1 to replace the alcohol in the tissue sample for transparent treatment. 4. Immersion wax: After the tissue sample was treated with xylene and alcohol solution, it was preheated in an oven at $57^{\circ} \mathrm{C}$, and then placed in soft wax a, soft wax b and hard wax for $1 \mathrm{~h}$ each time, so that the paraffin was fully immersed in the sample. 5. Embedding: The melted paraffin was poured into a carton, the wax-impregnated tissue was placed into it, then cooled in cold water, solidify and cut into cubes. 6 Slices: The embedded wax blocks were placed on a microtome for continuous sectioning and the cut paraffin pieces were placed in hot water to be flatly attached to the glass slides and dried in an oven at about $40{ }^{\circ} \mathrm{C} .7$. Dewaxing: The dried chips were first placed in a xylene solution for dewaxing and then immersed in absolute ethanol at 95\%, 85\%, 70\% and 50\% alcohol in each 2 min, and finally rinsed with distilled water. 8. Hematoxylin and Eosin (H \& E) staining: The dewaxed sections were first immersed in hematoxylin dye for $10 \mathrm{~min}$, then rinsed with distilled water, and placed in hydrochloric acid for 5 seconds. The sections were taken out and rinsed with tap water. Put it in 50\%, 70\%, 85\%, 95\% alcohol for $2 \mathrm{~min}$, and finally dye with $0.5 \%$ eosin alcohol. 9. Dehydrated and transparent: The stained slices were dehydrated by placing alcohol in different solubility and then placed in a xylene solution for transparent treatment. 10. Sealing: Neutral resin is dropped on the slice, then covered with a cover glass, and the sealed slice was observed under a microscope.

\section{Data analysis}

The data were analyzed using a one-way analysis of variance ANOVA procedure of SPSS software version 20.0 (SPSS Inc., Chicago, IL, USA). A probability value of $p$ valve $<0.05$ was considered statistically significant and were differences between means was noticeable, Duncan multiple range tests (DMRT) was employed to ascertain the difference among the treatments.

\section{Results}

\section{Growth performance of weaning piglets}

As shown in Table 2, the addition of the M6 and M12 alfalfa fibre to the diet increased the ADG in piglets. However, there was a decrease in the ADG at M18 alfalfa fibre supplementation. There was no significant difference $(\mathrm{P}>0.05)$ between the M0 and the other treatment groups however the M18 group was significantly lower $(\mathrm{P}<0.05)$ than the M6 and M12. The ADFI of the M6 group was higher than that of the other treatment groups. The ADFI of the M6 group was significantly higher $(\mathrm{P}<0.05)$ than the M0 group and the M18 group, but not significantly different $(\mathrm{P}>0.05)$ from the M12 group $(\mathrm{P}<0.05)$. There was no significant difference $(\mathrm{P}>0.05)$ in the FCR 
between the M0 group and the other treatment groups. The M6 group recorded the highest FCR and the M12 group had the lowest FCR.

Table 2. Effects of alfalfa fibre on the growth performance of piglets

\begin{tabular}{c|c|c|c|c}
\hline Items & M0 & M6 & M12 & M18 \\
\hline ADG (kg) & $0.44 \pm 0.08^{\mathrm{ab}}$ & $0.51 \pm 0.03^{\mathrm{a}}$ & $0.47 \pm 0.06^{\mathrm{a}}$ & $0.37 \pm 0.03^{\mathrm{b}}$ \\
ADFI (kg) & $0.96 \pm 0.18^{\mathrm{b}}$ & $1.18 \pm 0.11^{\mathrm{a}}$ & $1.02 \pm 0.14^{\mathrm{ab}}$ & $0.82 \pm 0.05^{\mathrm{b}}$ \\
FCR & $2.19 \pm 0.09$ & $2.31 \pm 0.19$ & $2.14 \pm 0.06$ & $2.22 \pm 0.13$ \\
\hline
\end{tabular}

In the same row, values with different small letter superscripts mean a significant difference $(\mathrm{P}<0.05)$, while with the same or no letter superscripts mean no significant $(\mathrm{P}>0.05)$. ADG: average daily gain, ADFI: average daily feed intake, FCR: feed conversion ratio. M0: 0.00\% alfalfa diet, M6: 6.00\% alfalfa diet, M12: $12.00 \%$ alfalfa diet, M18: $18.00 \%$ alfalfa diet.

\section{Nutrient digestion of weaning piglets}

The effect of dietary alfalfa fibre supplementation on nutrient digestibility of piglets was shown in Table 3. The digestibility of $\mathrm{CP}$ in piglets increased with the increase in the proportion of alfalfa fibre in the diet, but there was no significant effect $(\mathrm{P}>0.05)$ among treatments. The digestibility of $\mathrm{CF}$ increases first, and then decreases with the addition of high concentrations of alfalfa to the meal. There was no significant difference $(\mathrm{P}>0.05)$ between the treatment groups. The digestibility of DM in M6 group was higher than the other treatment groups and significantly different $(\mathrm{P}<0.05)$ from the M12 group and the M18 group but not different $(\mathrm{P}>0.05)$ from the M0 group. The M0 group was significantly different from the M12 group.

Table 3. Dietary supplementation of alfalfa fibre on nutrient digestibility of piglets (\%)

\begin{tabular}{c|c|c|c|c}
\hline Items & M0 & M6 & M12 & M18 \\
\hline CP & $79.72 \pm 1.19$ & $80.99 \pm 1.12$ & $81.93 \pm 2.53$ & $83.15 \pm 2.03$ \\
CF & $47.80 \pm 1.70$ & $49.37 \pm 0.61$ & $47.72 \pm 0.93$ & $46.95 \pm 5.10$ \\
DM & $82.29 \pm 0.77^{\mathrm{ab}}$ & $82.63 \pm 1.30^{\mathrm{a}}$ & $79.76 \pm 0.82^{\mathrm{c}}$ & $80.22 \pm 1.39^{\mathrm{bc}}$ \\
\hline
\end{tabular}

In the same row, values with different small letter superscripts mean a significant difference $(\mathrm{P}<0.05)$ while with the same or no letter superscripts mean no significant $(\mathrm{P}>0.05)$. CP: crude protein, $\mathrm{CF}$ : crude fibre, DM: dry matter. M0: 0.00\% alfalfa diet, M6: 6.00\% alfalfa diet, M12: $12.00 \%$ alfalfa diet, M18: $18.00 \%$ alfalfa diet.

\section{Nitrogen metabolism of piglets}

As shown in Table 4, the intake of $\mathrm{N}$ in each group varied due to the difference in feed consumption of piglets. The $\mathrm{N}$ intake in M12 was higher and significantly different $(\mathrm{P}<0.05)$ from the M18 group but not significantly different $(\mathrm{P}>0.05)$ from the M0 and M12. The fecal N content of piglets decreased with the increase in the concentration of alfalfa fibre in the diet. The fecal $\mathrm{N}$ content in the M0 was higher and significantly different $(\mathrm{P}<0.05)$ from the M12 and M18, but not significantly different $(\mathrm{P}>0.05)$ from the M6. The urine N content in the M18 was higher and significantly different $(\mathrm{P}<0.05)$ from the M6 group, but not significantly different $(\mathrm{P}>0.05)$ from the M0 and M12. The apparent $\mathrm{N}$ digestibility and $\mathrm{N}$ deposition were higher in the M12 in comparison with the other treatment groups. The apparent $\mathrm{N}$ digestibility in the M12 
was significantly different $(\mathrm{P}<0.05)$ from the $\mathrm{M} 0$, but not significantly different from the other two treatment groups, while the $\mathrm{N}$ deposition in the M12 was significantly different from the M18, but not significantly different $(\mathrm{P}>0.05)$ from the M0 and M6. The $\mathrm{N}$ deposition rate and $\mathrm{N}$ utilization rate in the M6 were significantly higher $(\mathrm{P}<0.05)$ in comparison with the $\mathrm{M} 0$ and $\mathrm{M} 18$, but not significantly different $(\mathrm{P}>0.05)$ from the M12 group.

Table 4. Effects of alfalfa fibre supplementation on $\mathrm{N}$ metabolism in piglets

\begin{tabular}{c|c|c|c|c}
\hline Items & M0 & M6 & M12 & M18 \\
\hline N intake (g/d) & $44.26 \pm 1.15^{\mathrm{ab}}$ & $45.28 \pm 1.58^{\mathrm{ab}}$ & $47.78 \pm 2.86^{\mathrm{a}}$ & $42.08 \pm 4.22^{\mathrm{b}}$ \\
$\mathrm{N}$ in feces (g/d) & $4.29 \pm 0.40^{\mathrm{a}}$ & $3.85 \pm 0.08^{\mathrm{ab}}$ & $3.76 \pm 0.20^{\mathrm{b}}$ & $3.64 \pm 0.11^{\mathrm{b}}$ \\
$\mathrm{N}$ in urine (g/d) & $9.24 \pm 0.31^{\mathrm{ab}}$ & $7.21 \pm 1.16^{\mathrm{b}}$ & $8.92 \pm 1.66^{\mathrm{ab}}$ & $9.52 \pm 1.01^{\mathrm{a}}$ \\
$\mathrm{N}$ apparent digestibility (\%) & $90.30 \pm 1.03^{\mathrm{b}}$ & $91.50 \pm 0.32^{\mathrm{ab}}$ & $92.13 \pm 0.62^{\mathrm{a}}$ & $91.32 \pm 0.62^{\mathrm{ab}}$ \\
N deposition (g/d) & $30.73 \pm 1.68^{\mathrm{ab}}$ & $33.58 \pm 1.46^{\mathrm{a}}$ & $34.47 \pm 2.01^{\mathrm{a}}$ & $28.91 \pm 2.68^{\mathrm{b}}$ \\
$\mathrm{N}$ deposition rate (\%) & $69.41 \pm 2.03^{\mathrm{bc}}$ & $74.14 \pm 0.76^{\mathrm{a}}$ & $72.17 \pm 1.99^{\mathrm{ab}}$ & $68.73 \pm 0.54^{\mathrm{c}}$ \\
$\mathrm{N}$ utilization rate (\%) & $76.85 \pm 1.54^{\mathrm{b}}$ & $81.03 \pm 0.79^{\mathrm{a}}$ & $78.33 \pm 2.12^{\mathrm{ab}}$ & $75.27 \pm 1.10^{\mathrm{b}}$ \\
\hline
\end{tabular}

In the same row, values with different small letter superscripts mean a significant difference $(\mathrm{P}<0.05)$ while with the same or no letter superscripts mean no significant $(\mathrm{P}>0.05)$. N: nitrogen. M0: $0.00 \%$ alfalfa diet, M6: 6.00\% alfalfa diet, M12: 12.00\% alfalfa diet, M18: $18.00 \%$ alfalfa diet.

\section{Blood biochemical parameters of piglets}

As shown in Table 5, the concentrations of albumin, globulin, and total protein increased first and then decreases with the increase in alfalfa fibre in the diet of piglets.

Table 5. Effects of alfalfa fibre on blood biochemical indexes of weaning piglets

\begin{tabular}{c|c|c|c|c}
\hline Items & M0 & M6 & M12 & M18 \\
\hline Albumin $(\mathrm{g} / \mathrm{L})$ & $24.0 \pm 0.82^{\mathrm{b}}$ & $25.0 \pm 2.16^{\mathrm{b}}$ & $29.5 \pm 3.79^{\mathrm{a}}$ & $25.81 \pm 3.19^{\mathrm{b}}$ \\
Globulin $(\mathrm{g} / \mathrm{L})$ & $32.4 \pm 0.70$ & $33.0 \pm 1.37$ & $32.85 \pm 4.9$ & $32.73 \pm 3.78$ \\
Total protein $(\mathrm{g} / \mathrm{L})$ & $56.4 \pm 0.98$ & $58.0 \pm 2.60$ & $62.35 \pm 8.47$ & $57.48 \pm 3.70$ \\
Blood glucose $(\mathrm{mmol} / \mathrm{L})$ & $3.87 \pm 0.26$ & $3.75 \pm 0.56$ & $3.78 \pm 0.55$ & $3.92 \pm 0.33$ \\
Urea N (mmol/L) & $4.64 \pm 0.40^{\mathrm{a}}$ & $3.39 \pm 0.06^{\mathrm{b}}$ & $4.08 \pm 0.02^{\mathrm{ab}}$ & $4.29 \pm 0.41^{\mathrm{a}}$ \\
Triglyceride $(\mathrm{mmol} / \mathrm{L})$ & $0.60 \pm 0.03^{\mathrm{a}}$ & $0.56 \pm 0.36^{\mathrm{a}}$ & $0.47 \pm 0.06^{\mathrm{b}}$ & $0.58 \pm 0.06^{\mathrm{a}}$ \\
Cholesterol $(\mathrm{mmol} / \mathrm{L})$ & $2.3 \pm 0.06$ & $2.19 \pm 0.16$ & $2.06 \pm 0.14$ & $2.18 \pm 0.32$ \\
Aspartate aminotransferase $(\mu / \mathrm{L})$ & $48.0 \pm 3.16$ & $46.0 \pm 3.74$ & $47.5 \pm 6.45$ & $48.5 \pm 7.77$ \\
Alanine aminotransferase $(\mu / \mathrm{L})$ & $42.5 \pm 2.89$ & $39.5 \pm 2.65$ & $41.25 \pm 4.27$ & $40.75 \pm 4.5$ \\
\hline
\end{tabular}

In the same row, values with different small letter superscripts mean a significant difference $(\mathrm{P}<0.05)$, while with the same or no letter superscripts mean no significant $(\mathrm{P}>0.05)$. M0: $0.00 \%$ alfalfa diet, M6: $6.00 \%$ alfalfa diet, M12: $12.00 \%$ alfalfa diet, M18: $18.00 \%$ alfalfa diet.

The albumin concentration in the M12 group was significantly different $(\mathrm{P}<0.05)$ from the other treatment groups. There was no significant difference $(\mathrm{P}>0.05)$ in the globulin and total protein levels between the treatment groups. However, the highest globulin concentration was recorded in the M6, while the highest total protein level was registered in the M12. There were no significant differences $(\mathrm{P}>0.05)$ in the blood glucose, cholesterol, aspartate aminotransferase, and alanine aminotransferase 
concentrations between the groups. The highest blood glucose and aspartate aminotransferase concentrations were observed in the M18 group, while the highest alanine aminotransferase was observed in the M0 group. While the highest cholesterol was observed in the M0 group. The concentration of urea $\mathrm{N}$ decreased with the addition of alfalfa fibre to the diet and later increased with the increase in the proportion of alfalfa fibre, but not higher than the control. The urea $\mathrm{N}$ level in the M6 was significantly lower $(\mathrm{P}<0.05)$ in comparison with the M0 and M18, but not significantly different $(\mathrm{P}>0.05)$ from the M12 group. The triglyceride concentration in the M12 was significantly lower $(\mathrm{P}<0.05)$ in comparison with the other three groups. The M0 recorded the highest triglyceride concentration.

\section{Intestinal development of weaning piglets}

As shown in Table 6 and Figure 2, the M12 group registered the highest VH in the duodenum of each treatment group and the $\mathrm{VH}$ of the M12 was significantly higher $(\mathrm{P}<0.05)$ than the $\mathrm{VH}$ in the M18, but not significantly different $(\mathrm{P}>0.05)$ from the M0 and M6. The CD of the duodenum was higher in the M18, but there was no significant difference $(\mathrm{P}>0.05)$ between the treatment groups. The $\mathrm{VH}-\mathrm{CD}$ ratio of the duodenum was significantly lower $(\mathrm{P}<0.05)$ in the $\mathrm{M} 0$ group in comparison with the other groups. From Table 6 and Figure 3, the VH in the jejunum was significantly higher $(\mathrm{P}<0.05)$ in the M12 group in comparison with the M0, but not significantly different from the M6 and M18. There was no significant difference $(\mathrm{P}>0.05)$ in the $\mathrm{CD}$ of the jejunum between the treatment groups. However, the M12 recorded the highest $\mathrm{CD}$. The $\mathrm{VH}-\mathrm{CD}$ ratio of the jejunum was significantly higher $(\mathrm{P}<0.05)$ in the M18 in comparison with the M0 and M6, but not significantly different $(\mathrm{P}>0.05)$ from the M12. From Table 6 and Figure 4, the VH of the ileum first increased with the increase in the concentration of alfalfa fibre in the diet and later decreased at higher dietary alfalfa fibre levels. However, there was no significant difference $(\mathrm{P}>0.05)$ between the treatment groups. The $\mathrm{CD}$ of the ileum was significantly higher $(\mathrm{P}<0.05)$ in the M12 in comparison with the M0 and M6, but not significantly different $(\mathrm{P}>0.05)$ from the M18. The VH - CD ratio of the ileum was higher in the M6, but there was no significant difference $(\mathrm{P}>0.05)$ between the treatment groups.

Table 6. Effect of alfalfa fibre supplementation on intestinal development of weaning piglet

\begin{tabular}{c|c|c|c|c|c}
\hline Item & Properties & M0 & M6 & M12 & M18 \\
\hline \multirow{5}{*}{ Duodenum } & VH $(\mu \mathrm{m})$ & $561.48 \pm 19.36^{\mathrm{ab}}$ & $563.85 \pm 44.35^{\mathrm{ab}}$ & $594.18 \pm 28.78^{\mathrm{a}}$ & $524.19 \pm 44.35^{\mathrm{b}}$ \\
& $\mathrm{CD}(\mu \mathrm{m})$ & $247.76 \pm 19.46$ & $245.62 \pm 33.16$ & $237.08 \pm 33.29$ & $287.64 \pm 58.69$ \\
& $\mathrm{VH}: \mathrm{CD}$ & $1.10 \pm 0.10^{\mathrm{b}}$ & $1.44 \pm 0.22^{\mathrm{a}}$ & $1.57 \pm 0.24^{\mathrm{a}}$ & $1.60 \pm 0.1^{\mathrm{a}}$ \\
\hline \multirow{5}{*}{ Jejunum } & $\mathrm{VH}(\mu \mathrm{m})$ & $459.25 \pm 40.95^{\mathrm{b}}$ & $489.24 \pm 66.61^{\mathrm{ab}}$ & $538.94 \pm 37.89^{\mathrm{a}}$ & $481.25 \pm 30.18^{\mathrm{ab}}$ \\
& $\mathrm{CD}(\mu \mathrm{m})$ & $187.92 \pm 22.65$ & $204.91 \pm 27.69$ & $223.69 \pm 59.21$ & $194.63 \pm 66.64$ \\
& $\mathrm{VH}: \mathrm{CD}$ & $2.47 \pm 0.37^{\mathrm{b}}$ & $2.44 \pm 0.62^{\mathrm{b}}$ & $2.54 \pm 0.68^{\mathrm{ab}}$ & $2.71 \pm 0.92^{\mathrm{a}}$ \\
\hline \multirow{3}{*}{ Ileum } & $\mathrm{VH}(\mu \mathrm{m})$ & $394.61 \pm 34.41$ & $406.16 \pm 29.21$ & $426.87 \pm 50.71$ & $369.46 \pm 30.90$ \\
& $\mathrm{CD}(\mu \mathrm{m})$ & $182.37 \pm 37.81^{\mathrm{b}}$ & $190.60 \pm 45.86^{\mathrm{b}}$ & $253.85 \pm 15.13^{\mathrm{a}}$ & $244.03 \pm 14.25^{\mathrm{ab}}$ \\
& $\mathrm{VH}: \mathrm{CD}$ & $2.20 \pm 0.37$ & $2.23 \pm 0.59$ & $1.68 \pm 0.13$ & $1.51 \pm 0.03$ \\
\hline
\end{tabular}

In the same row, values with different small letter superscripts mean a significant difference $(\mathrm{P}<0.05)$, while with the same or no letter superscripts mean no significant $(\mathrm{P}>0.05)$. VH: Villus Height, CD: Crypt Depth, VH:CD means the ratio of the Villus Height to Crypt Depth. M0: $0.00 \%$ alfalfa diet, M6: $6.00 \%$ alfalfa diet, M12: $12.00 \%$ alfalfa diet, M18: $18.00 \%$ alfalfa diet 

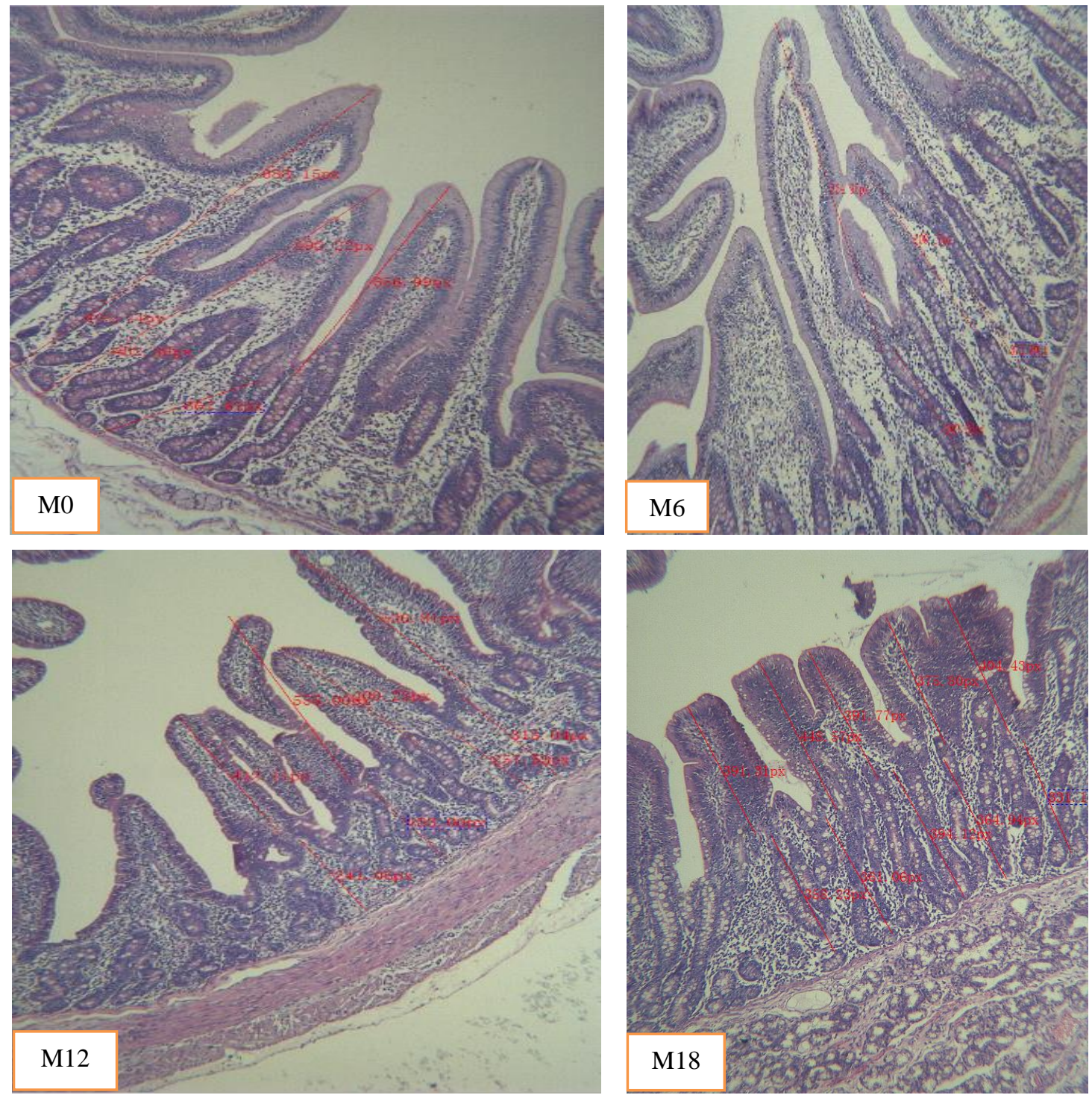

Figure 1. Intestinal morphometry analysis of the villus height, crypt depth, and villus height to crypt ratio in the duodenum among the different treatment groups
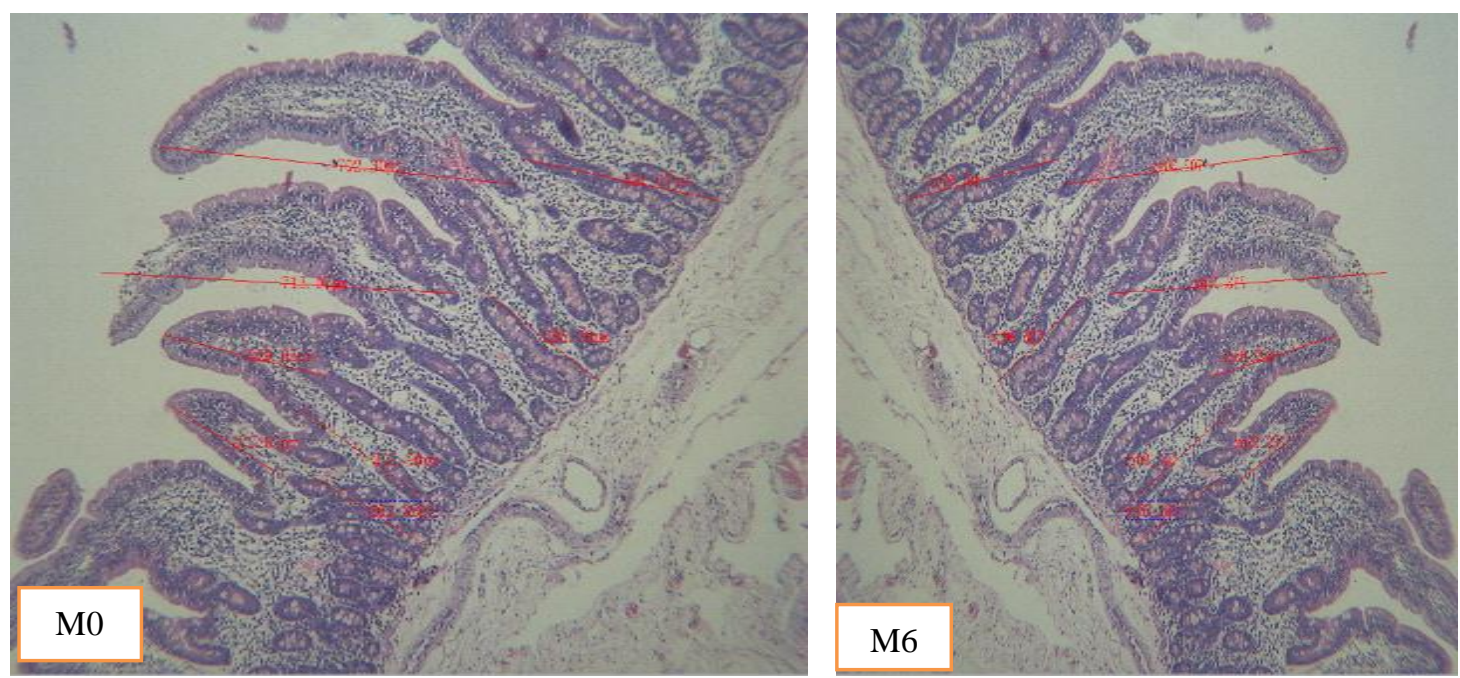

APPLIED ECOLOGY AND ENVIRONMENTAL RESEARCH 17(2):2275-2295.

http://www.aloki.hu • ISSN 15891623 (Print) • ISSN 17850037 (Online)

DOI: http://dx.doi.org/10.15666/aeer/1702_22752295

(c) 2019, ALÖKI Kft., Budapest, Hungary 

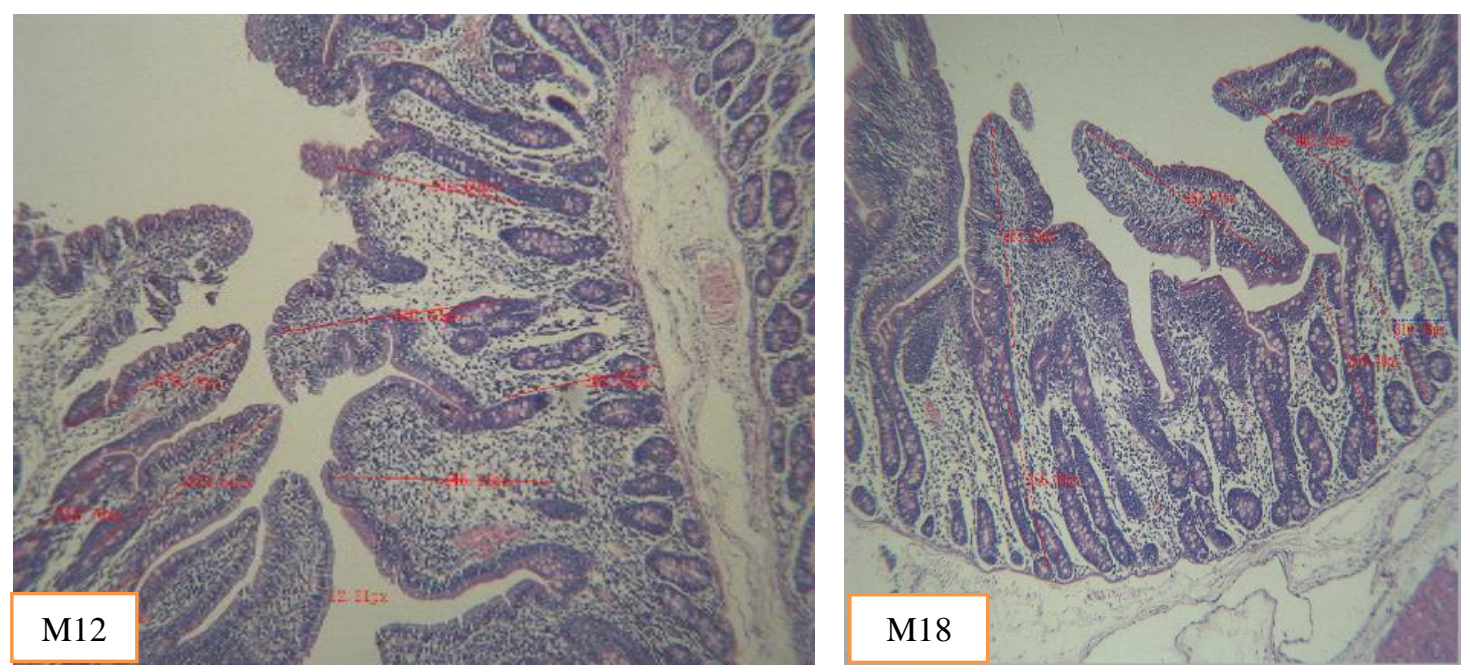

Figure 2. Morphological analysis of the villus height, crypt depth, and villus height to crypt ratio in the jejunum among the different treatment groups
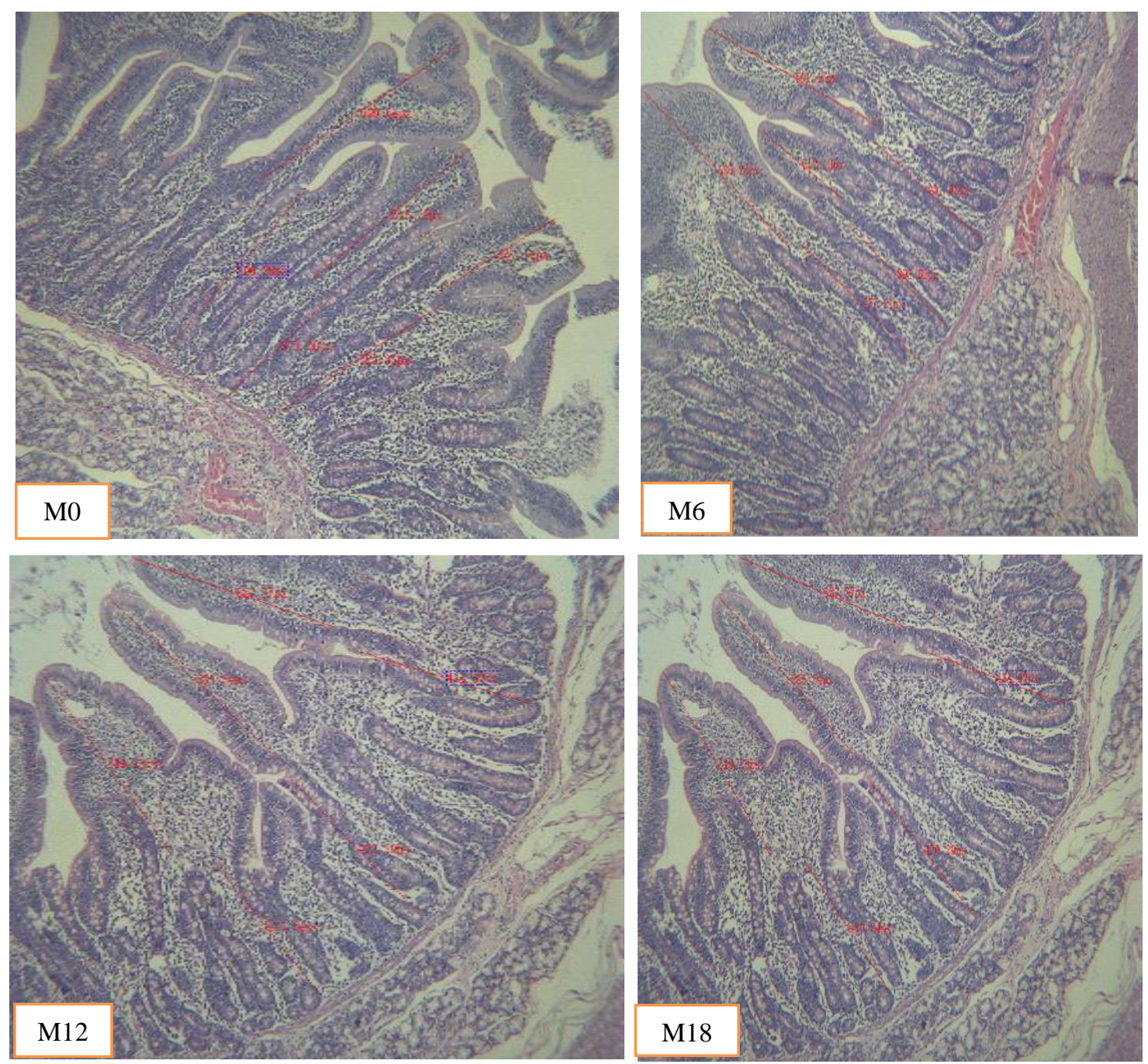

Figure 3. Morphological analysis of the villus height, crypt depth, and villus height to crypt ratio in the ileum among the different treatment groups 


\section{Discussion}

\section{Growth performance of pigs}

The current study showed that the addition of different dietary concentrations of alfalfa fibre to the diet of piglets promotes their growth performance. However, at higher concentrations, there was a downward trend in the growth performance of piglets. These findings indicated that supplementing the optimum concentrations (6.00$12.00 \%$ ) of alfalfa fibre to the diet of piglets will significantly promote the growth and development of piglets. Our results were in agreement with the findings of (Che et al., 2018; Adams et al., 2018a; Wang et al., 2010; Yuan et al., 2006). In supplementing Astragalus membranaceus fibre to the diet of weaning piglets (Che et al. 2018) and Adams et al. (2018a) observed an increase in the growth performance of piglets weaned at 28 days old. Similarly, Yuan et al. (2006) observed an increase in the growth performance of piglets after feeding on Astragalus polysaccharides. Also, after feeding on both Astragalus membranaceus roots powder and Astragalus polysaccharide, Wang et al. (2010) observed an increase in the growth performance of broiler chicks. Wang et al. (2016) reported an increase in the growth performance of weaning pigs fed with sugar beet pulp. Chen et al. (2016) reported that adding alfalfa flavonoid to the diet of Yangzhou geese increased their growth performance. However, supplementing higher concentration $(18.00 \%)$ of alfalfa fibre will have a detrimental effect on the growth performance of weaning piglets. This is because weaning piglets cannot utilize the high fibre content present at the maximal concentrations of alfalfa fibre due to the immature gastrointestinal tract and less gut microbial composition and diversity (Che et al., 2018). Similarly, Chen et al. (2017) and Adams et al. (2018b) indicated that piglets have immature gastrointestinal systems and adapting to a less digestible solid feed such as dietary fibre seems challenging. The supplementation of dietary fibre to the diet of piglets promotes the growth and health of piglets, as these fibre components can be fermented by microorganisms in the intestinal tract to produce large volumes of shortchain fatty acid, that serves as the main energy source for weaning piglets (Christensen et al., 1999; Che et al., 2018), reduce the population of enteric bacteria in the gut that causes piglet diarrhea during weaning ( $\mathrm{Li}$ et al., 2011; Che et al., 2018). In contrast to our findings, Wellock et al. (2008) observed a decrease in the growth performance of piglets after feeding on a dietary fibre supplemented diet. In addition, there was no effect on the growth performance of lambs after feeding on a diet supplemented with sugar beet pulp and roasted canola seed (Asadollahi, et al., 2018). Also, Jin et al. (2018) observed no change in the growth performance of growing lambs after feeding on a dietary Urtica cannabina supplemented diet. Moreover, dietary supplementation of alfalfa saponins had no effect on the growth performance of lambs (Liu et al., 2018). Furthermore, Wang et al. (2018) observed no effect on the ADG and ADFI in piglets after feeding on alfalfa containing diet. Jiang et al. (2012) observed no change in the growth performance of ducks fed with alfalfa meal. The difference between our findings and these studies may be due to the difference in animal species and the fibre source or alfalfa plant concentration applied. Therefore, dietary inclusion of alfalfa fibre at an optimum level can positively promote the growth performance of piglets.

\section{Nutrient digestion of piglets}

Che et al. (2018) indicated that the main importance of any nutritional supplement added to an animal's diet was as a result of its ability to be utilized by the animal. 
Hence, the digestibility of nutritional components of a dietary supplement is a vital parameter in evaluating its inclusion in the diet. The findings of this study indicated that the supplementation of alfalfa fibre to the diet of piglets increased their nutrient digestibility. This study showed that the digestibility of CP increased with the increase in alfalfa fibre concentrations in the diet. Also, the $\mathrm{CF}$ and $\mathrm{DM}$ digestibility first increased with the addition of alfalfa fibre and then decreased as the concentration increases. Similarly, Jin et al. (2018) observed an increase in the CP digestibility after supplementing Urtica cannabina in the diet of growing lambs. In addition, Lara et al. (2018) observed an increase in nutrient digestibility in wethers after feeding on corn silage inoculated with Lactobacillus plantarum and Bacillus subtilis. Moreover, the supplementation of dietary alfalfa saponins in the diet of lambs increased their nutrient digestibility. Furthermore, Ebrahimi et al. (2018) reported a decrease in the nutrient digestibility of neonatal calves after feeding on Trachyspermum ammi and Thymus vulgaris oils in their diets. The supplementation of alfalfa fibre promotes the development of piglets' intestinal tract and increase the digestive function of piglets. The alfalfa fibre is a high-quality protein feed hence increasing its supplementation may increase the nutrient digestibility of piglet, especially CP digestibility. However, higher fibre content in the diet may decrease the bioavailability of some key nutritional components such as some minerals and vitamins (Adams et al., 2018b) and reduce the proportion of digestible substances in food and digestive energy (Adams et al., 2018c). In contrast to our findings, Che et al. (2018) reported a decrease in nutrient digestibility after feeding Astragalus membranaceus fibre to weaning piglets. Wang et al. (2016) reported a decrease in nutrient digestibility in weaning piglets after feeding on a sugar beet pulp. Also, Jørgensen et al. (1996) reported a low nutrient digestibility in pigs fed with high fibre concentrated diet. In addition, Dilger et al. (2004) fed high soy hull fibre to pigs and observed low DM digestibility. Furthermore, dietary fibre affects the function of the gastrointestinal tract, as indicated by low nutrient digestibility and accessibility of feeds with high-fibre levels (Bikker et al., 2006; Adams et al., 2018c). Pinheiro et al. (2018) reported that dietary supplementation of higher alfalfa concentrations in the diet of European adult rabbits had no effect on the digestibility of dietary components. Moreover, dietary fibre intake impacts the various methods in nutrients absorption and digestibility and this may lead to a delay in the glycemic response (Adams et al., 2018b). As reported in a review by Adams et al. (2018b, c), dietary fibre and prebiotics impact the health of the host animal by regulating blood glucose or insulin levels, stool bulking effects, enhancing the acidity of the gut, shortchain fatty acids synthesis, reducing intestinal transit time, inspiring the growth of intestinal microbes, and increase the production of blood biochemical components. Therefore, the effects of dietary fibre on nutrient digestibility may depend on the dietary fibre source or form, the nutritional component, the age of the animal, and the health of the animal.

\section{Nitrogen metabolism and blood biochemical parameters in piglets}

The difference in dietary feed consumption influence the rate of $\mathrm{N}$ metabolism in animals. The results of this study showed that dietary supplementation of alfalfa fibre increased the $\mathrm{N}$ metabolism in piglets. The piglets that were fed with $12 \%$ of alfalfa fibre (M12) had the highest $\mathrm{N}$ intake. Meanwhile, the fecal $\mathrm{N}$ content in piglets decreased with the increase in the concentration of alfalfa fibre in the diet. The highest urine $\mathrm{N}$ content was observed in the M18 group while the apparent $\mathrm{N}$ digestibility and $\mathrm{N}$ 
deposition were observed in the M12 group. According to the test results, we observed that the addition of alfalfa fibre to the piglet's diet maintained the normal growth performance of piglets. Therefore, optimum dietary fibre concentration can promote the $\mathrm{N}$ utilization in the body, but the excessive concentration of alfalfa may reduce the time during which the chyme stays in the intestine hence reduce the $\mathrm{N}$ utilization rate. In addition, urinary urea levels may rapidly decompose to ammonia by exposing to the environment (Aarnink and Verstegen, 2007), causing environmental pollution. In this experiment, the addition of alfalfa fibre reduced the emission of fecal $\mathrm{N}$ and urinary $\mathrm{N}$, hence reduced environmental pollution. Therefore, improving the fibre levels of the diet may be an important means of reducing the $\mathrm{N}$ emissions from pig farms.

Blood contains various proteins, sugars, lipids, and other metabolic substances such as enzymes and hormones which affect the growth and metabolism of nutrients in the body. Blood biochemical indicators influence blood levels, animal health, and impacts growth and nutrient regulation in animals. The findings of this study indicated that the supplementation of alfalfa fibre to the diet increased the albumin, globulin, and total protein concentrations in the blood of piglets. The addition of the optimum (6.00$12.00 \%$ ) alfalfa fibre to the diet of piglets decreased the blood glucose, cholesterol, aspartate aminotransferase, and alanine aminotransferase in piglets, but higher alfalfa fibre increased blood glucose and aspartate aminotransferase concentration. Meanwhile, the triglyceride levels decreased with the addition of alfalfa fibre to the diet. The serum total protein, including albumin and globulin relate to the protein synthesis in the body. It influences protein concentration, synthesis, and functions in immune responses, transportation, and coagulation (Paschke et al., 2010). The results of this experiment indicated that supplementing alfalfa fibre to the diet may increase the total protein levels in pigs. Similarly, Chen et al. (2016) reported that the supplementation of alfalfa flavonoid to the diet of Yangzhou geese has no adverse effects on the total protein metabolism and liver functions. Furthermore, these authors reported that adding 150 to $450 \mathrm{mg} / \mathrm{kg}$ alfalfa flavonoids increased serum total protein concentration in geese (Chen et al., 2016). However, when the amount of alfalfa fibre reached $18 \%$, the total protein content of the serum began to decrease. The addition of fibre to the diet has no adverse effects on the metabolic processes in piglets but excess fibre may attenuate the metabolic functions in piglets. Therefore, supplementing the optimum concentration of alfalfa fibre will promote the health and productivity of pigs. Serum urea $\mathrm{N}$ is the final metabolite of protein and amino acid catabolism in animals (Chen et al., 2016). Its content can accurately reflect the nutritional status of an animal and the absorption and utilization of protein in the body. Studies have shown that when serum urea $\mathrm{N}$ decreases, there may be a decrease in the protein metabolism of the body and increase in the $\mathrm{N}$ deposition (Paschke et al., 2010). Also, the findings of this experiment indicated that the urea $\mathrm{N}$ composition of the trial groups was lower in comparison with the M0. The M6 group had the lowest urea $\mathrm{N}$ content and the highest $\mathrm{N}$ deposition. Contrarily to our observation, Chen et al. (2016) observed an increase in the serum urea $\mathrm{N}$ after adding alfalfa flavonoid to the diet of Yangzhou geese. Also, Qiu et al. (2009) reported an increase in the serum urea $\mathrm{N}$ concentrations after feeding protein diet supplemented with dietary zinc. This further confirms the relationship between serum urea $\mathrm{N}$ and $\mathrm{N}$ deposition in animals. The blood glucose is mainly metabolized in the hepatic glycogen decomposition and intestinal absorption. It forms the main tissue components and energy metabolic substrates of the body. Therefore, changes in the blood glucose levels may influence the dynamic balance between the sugar absorption, 
transport, and metabolism in the body. The findings of this study further showed that there was no significant effect on the blood glucose concentration in piglets after feeding on alfalfa fibre, this indicates that the rate of energy conversion between the treatment groups maintained a dynamic equilibrium. The cholesterol and triglyceride concentrations in the serum can reflect the total lipid metabolism in the body (Chen et al., 2016). The higher the cholesterol or triglyceride content, the higher the body's ability to metabolize fat. The results of this experiment indicated that alfalfa fibre may reduce the cholesterol and triglyceride concentrations in the blood of weaning piglets, hence indicating that alfalfa fibre has a certain lipid-lowering effect. Similarly, Chen et al. (2016) deemed that the addition of alfalfa flavonoid decreased the triglycerides and total cholesterol levels in Yangzhou geese. Similarly, Zhou (2011) reported that an increase in cholesterol metabolism and a reduction in the cholesterol deposition of the body, thus promoting meat quality parameters. Aspartate aminotransferase and alanine aminotransferase are involved in the metabolism of amino acids in the body and are important indicators for evaluating liver functions (Chen et al., 2016). The addition of alfalfa fibre to the diet had no significant effect on the two transaminase enzymes, hence indicating that high fibre level in the diets had no effect on the amino acid metabolism of the body. Contrarily to our observation, Chen et al. (2016) observed that the addition of alfalfa flavonoid significantly increased the levels of aspartate aminotransferase and alanine aminotransferase in comparison with the control group. Also, there was an increase in the aspartate aminotransferase and alanine aminotransferase level when rapeseeds diet was fed to geese (Wang et al., 2015a) and alfalfa diet fed to sheep (Wang et al., 2015b). The difference between our findings and that of these authors may be due to the form of alfalfa used and the experimental animal involved. Therefore, adding alfalfa fibre may promote the $\mathrm{N}$ metabolism, improve biochemical parameter, and no adverse effect on the amino acid metabolism.

\section{Intestinal morphometry of piglets}

Studies have indicated that dietary fibre is a valuable nutrient for the prevention of intestinal disorders and improving intestinal health in both humans and animals (Ingvar, 2004). The small intestine is the main site for digestion and absorption of various nutrients in the diet. The villi are the functional units of the small intestine and the height of the villi can affect the nutrient absorption abilities of the small intestines. The villus atrophy occurs when the cells at the top of the villi are detached or the rate of cell regeneration is decreased and the number of mature cells is reduced leading to gastrointestinal inflammatory disease (Geboes et al., 2018). The intestinal glands and its $\mathrm{CD}$ reflect the maturation rate of the cells and the deepening of the crypts means that the cell maturation rate decreases, therefore decreasing the rate of transport of substances from the epithelial cells to the top of the villi (Wallig, 2018). The ratio of the $\mathrm{VH}$ - CD influence the functions of the small intestine (Hu et al., 2018). The higher the ratio of the $\mathrm{VH}-\mathrm{CD}$, the higher the intestinal mucosal functions and the absorption capacity of the small intestine. However, lower VH - CD indicates that the intestinal mucosa is damaged and the absorption capacity of the intestine decreases ( $\mathrm{Hu}$ et al., 2018). The results of this study showed that the VH of the duodenum, jejunum, and the ileum was higher in the M6 and M12 in comparison with the control group. In agreement with our study was the findings of Xia et al. (2005) who reported that the supplementation of copper-bearing montmorillonite to the diet of weaning piglets significantly increased the $\mathrm{VH}$ and the $\mathrm{VH}-\mathrm{CD}$ ratio in the small intestinal mucosa 
compared to the control group. Meanwhile, Xia and colleagues observed no significant effects on the small intestinal morphology after supplementing $\mathrm{CuSO}_{4}$ to the diet of piglets (Xia et al., 2005). Similarly, Jiang et al. (2012) reported that there was a significant difference in the $\mathrm{VH}, \mathrm{CD}$, and $\mathrm{VH}-\mathrm{CD}$ ratio in the duodenum, jejunum, and ileum of ducks fed with different concentrations of alfalfa meal. Broiler chickens fed with wet diet had high VH and low CD in the duodenum, jejunum, ileum, cecum, and the colon in comparison with those fed with dry diet (Yasar and Forbes, 1999). High VH was observed in the duodenum after feeding birds with Bacillus subtilis (Samanya and Yamauch, 2002) and yeast cell wall (Zhang et al., 2005). Also, Hedemann et al. (2006) observed that feeding pigs with high-insoluble fibre diets may guard the small intestine against pathogenic bacteria by increasing the VH. In addition, Chen et al. (2013b) indicated that piglets that were fed with wheat bran fibre had a higher VH in the ileum than those fed with soybean fibre. These same authors found that the supplementation of wheat bran fibre and pea fibre in the diet of weaning piglets increased the number of mucosal goblet cells in the colon (Chen et al., 2013b). Furthermore, $\mathrm{Xu}$ et al. (2003) indicated that feeding fructooligosaccharide $(0.4 \%)$ to broilers increased the ileal $\mathrm{VH}, \mathrm{CD}$, and $\mathrm{VH}-\mathrm{CD}$ ratio. We observed that the $\mathrm{VH}$ of the duodenum and the ileum decreased at higher concentration of alfalfa fibre (M18) in comparison with the other groups. Xia et al. (2005) indicated that the digestive tract accommodates some stresses that relatively causes a deviation in the intestinal mucosa of piglets due to the close proximity of the mucosal surface of the intestinal components. The supplementation of dietary fibre levels in the diet promotes the development of the intestinal villi in piglets, but higher fibre content may lead to atrophy of the villi. The variations in the intestinal morphology such as shorter villus and deeper crypts have been related to the presence of toxins and other chemical agents (Xu et al., 2003). Gerritsen et al. (2012) showed that dietary fibre levels affect the changes in the intestinal morphology of animals, mainly due to the changes in the surface area of the intestines such as the height and number of villi. Kleessen et al. (2003) reported that feeding high fibre diets to pigs increased the VH of the ileum and jejunum, but had no significant effect. Also, the ileal VH - CD ratio in piglets fed with wheat bran fibre was higher than piglets that were fed with maize bran fibre (Chen et al., 2013a). In this study, the ratio of the VH - CD in the duodenum and jejunum increased with the increase in the supplementation of alfalfa fibre in the diet while in the ileum the highest VH - CD ratio was recorded in the M6 group. The above test results showed that a piglet fed diet with alfalfa as the main fibre source can promote the development of the small intestinal villi and improve nutrient digestibility and utilization rate. In contrast to our study, Nabizadeh (2012) reported that dietary supplementation of inulin in the diet of broiler chicks had no effect on $\mathrm{VH}, \mathrm{CD}$, and the $\mathrm{VH}-\mathrm{CD}$ ratio in the duodenum and jejunum on day 42 of age. In addition, cellulose supplementation significantly reduced the $\mathrm{VH}$ in both the jejunum and ileum (Chen et al., 2014). However, inulin inclusion significantly increased ileal VH in broiler chickens at 42 days of age (Chen et al., 2014). Studies have shown that the level of feed intake affects the height of the small intestinal villi and the depth of the crypt. The increase in feed intake promotes the development of the small intestine. The reason may be that some fibre components can regulate the composition of microorganisms in the intestine through fermentation to increase the intestinal VH and CD of animals (Jiang et al., 2012). The supplementation of fibre in the diet may stimulate volatile fatty acids produced by intestinal microbial fermentation, while butyric acid promotes the intestinal 
cell production, thereby deepening CD (Gidenne et al., 2002). Early weaning of piglets can cause stress induction in piglets which may cause changes to the intestinal morphology, atrophy of the small intestinal villi, and deepening of the crypts, hence affecting the body's absorption ability and utilization of nutrients and decreased immunity. Therefore, piglets weaning stress may be alleviated by appropriately raising the fibre level of the diet to maintain the intestinal health of piglets.

\section{Conclusion}

This experimental study showed that adding $6-12 \%$ of alfalfa fibre to the diet of weaning piglets may improve the growth and nutrient digestibility of piglets, reduce $\mathrm{N}$ emissions, and improve $\mathrm{N}$ utilization in piglets. Also, adding 6-12\% of alfalfa fibre to the diet of piglets may promote the utilization of protein and maintain the balance in glucose metabolism. At the same time improve the intestinal morphological structures and improve the digestion and absorption of the small intestine. Therefore, further research is recommended to elucidate the effects of alfalfa fibre on the gut microbial function with reference to nutrient digestibility and $\mathrm{N}$ metabolism in piglets.

Acknowledgements. This work was financially supported by the national key research and development program of China (2017YFD0502104), and the scientific project of Jilin province (20170309003NY \& 20180101023JC).

Conflict of interests. The authors declare that there is no conflict of interests.

\section{REFERENCES}

[1] Aarnink, A. J., Verstegen, M. W. (2007): Nutrition, key factor to reduce environmental load from pig production. - Livestock Science 109: 194-203.

[2] Adams, S., Che, D., Hailong, J., Zhao, B., Rui, H., Danquah, K., Qin, G. (2019a): Effects of Pulverized Oyster Mushroom (Pleurotus ostreatus) on Diarrhea Incidence, Growth Performance, Immunity, and Microbial Composition in Piglets. - Journal of the Science of Food and Agriculture. https://doi.org/10.1002/jsfa.9582.

[3] Adams,S., Yang, H., Che, D., Hailong, J., QIN, G. (2019b): Effects of high dietary copper supplementation on the copper accumulation and total copper content in fattening pigs. - Applied Ecology \& Environmental Research 7: 1401-1410. http://dx.doi.org/10.15666/aeer/1701_14011410.

[4] Adams, S., Che, D., Hailong, J., Han, R., Qin, G., Danquah, K. (2018a): Dietary supplementation of pulverised Astragalus membranaceus improved performance, immunity and diarrhoea incidence in weaned piglets. - Indian Journal of Animal Research. https://doi.org/10.18805/ijar.B-936.

[5] Adams, S., Che, D., Qin, G., Rui, H., Sello, C. T., Hailong, J. (2018b): Interactions of dietary fibre with nutritional components on gut microbial composition, function and health in monogastrics. - Current Protein \& Peptide Science 19: 1011-1023. DOI: 10.2174/1389203719666180508111843.

[6] Adams, S., Sello, C. T., Qin, G. X., Che, D., Han, R. (2018c): Does dietary fiber affect the levels of nutritional components after feed formulation? - Fibers 6: 29. https://doi.org/10.3390/fib6020029.

[7] Asadollahi, S., Ponnampalam, E. N., Sari, M., Erfanimajd, N. (2018): Effects of sugar beet pulp and roasted canola seed, on performance, rumen and small intestine digesta 
volatile fatty acid concentrations, and small intestine morphology of Arabian lambs. Livestock Science 216: 130-137.

[8] AOAC (1990): Official Methods of Analysis. 15th ed. - AOAC, Arlington, VA.

[9] Bach Knudsen, K. E. (1997): Carbohydrate and lignin contents of plant materials used in animal feeding. - Animal Feed Science \& Technology 67: 319-338.

[10] Bikker, P., Dirkzwager, A., Fledderus, J., Trevisi, P., Huërou- Luron, I. L., Lallès, J. P., Awati, A. A. (2006): In The effect of dietary protein and fermentable carbohydrates levels in newly weaned pigs on performance and intestinal characteristics. - Journal of Animal Science 84: 3337-3345. https://doi.org/10.2527/jas.2006-076.

[11] Che, D., Adams, S., Wei, C., Gui-Xin, Q., Atiba, E. M., Hailong, J. (2018): Effects of Astragalus membranaceus fiber on growth performance, nutrient digestibility, microbial composition, VFA production, gut $\mathrm{pH}$, and immunity of weaned pigs. MicrobiologyOpen, p. e00712. DOI: $10.1002 / \mathrm{mbo} 3.712$.

[12] Chen, L., Zhang, H., Gao, L., Zhao, F., Lu, Q., Sa, R. (2013a): Effect of graded levels of fiber from alfalfa meal on intestinal nutrient and energy flow, and hindgut fermentation in growing pigs. - Journal of Animal Science 91: 4757-4764.

[13] Chen, H., Chen, D., Michiels, J., De, S. S. (2013b): Dietary fiber affects intestinal mucosal barrier function by regulating intestinal bacteria in weaning piglets. - British Journal of Nutrition 78: 71-78.

[14] Chen, H., Mao, X. B., Che, L. Q., Yu, B., He, J., Yu, J., Chen, D. W. (2014): Impact of fiber types on gut microbiota, gut environment and gut function in fattening pigs. Animal Feed Science and Technology 195: 101-111.

[15] Chen, L., Xu, Y., Chen, X., Fang, C., Zhao, L., Chen, F. (2017): The maturing development of gut microbiota in commercial piglets during the weaning transition. Frontiers in Microbiology 8: 1688.

[16] Chen, Y., Gong, X., Li, G., Lin, M., Huo, Y., Li, S., Zhao, G. (2016): Effects of dietary alfalfa flavonoids extraction on growth performance, organ development and blood biochemical indexes of Yangzhou geese aged from 28 to 70 days. - Animal Nutrition 2: 318-322.

[17] Christensen, D. N., Knudsen, K. E. B., Wolstrup, J., Jensen, B. B. (1999): Integration of ileum cannulated pigs and in vitro fermentation to quantify the effect of diet composition on the amount of short-chain fatty acids available from fermentation in the large intestine. - Journal of the Science of Food and Agriculture 79: 755-762. https://doi.org/10.1002/(SICI)1097-0010(199904)79.

[18] Dilger, R. N., Sands, J. S., Ragland, D., Adeola, O. (2004): Digestibility of nitrogen and amino acids in soybean meal with added soyhulls12. - Journal of Animal Science 82: 715-724. https://doi.org/10.2527/2004.823715x.

[19] Ebrahimi, M. A., Sobhanirad, S., Bayat, A. R. (2018): Effects of Ajwain (Trachyspermum ammi) and Thyme (Thymus vulgaris) Oils on nutrients digestibility, blood parameters and growth performance of brown swiss neonatal calves. - Iranian Journal of Applied Animal Science 8: 387-395.

[20] Ensminger, M. E. (1992): Poultry Science: Feeds and Additives. 3th Ed. - Interstate Publishers, Inc., Danville, Illinois, USA

[21] Geboes, K., Dewit, O., Moreels, T. G., Faa, G., Jouret-Mourin, A. (2018): Inflammatory Bowel Diseases. - In: Jouret-Mourin, A. et al. (eds.) Colitis. Springer, Cham, pp. 107140.

[22] Gerritsen, R., van der Aar, P., Molist, F. (2012): Insoluble non-starch polysaccharides in diets for weaned piglets. - Journal of Animal Science 90: 318-320.

[23] Gidenne, T., Jehl, N., Segura, M., Michalet-Doreau, B. (2002): Microbial activity in the caecum of the rabbit around weaning: impact of a dietary fibre deficiency and of intake level. - Animal Feed Science and Technology 99(1-4): 107-118. 
[24] Griggs, J. P., Jacob, J. P. (2005): Alternatives to antibiotics for organic poultry production. - Journal of Applied Poultry Research 14: 750-756. https://doi.org/10.1016/S0377-8401(00)00183-8.

[25] Hassanat, F., Gervais, R., Benchaar, C. (2017): Methane production, ruminal fermentation characteristics, nutrient digestibility, nitrogen excretion, and milk production of dairy cows fed conventional or brown midrib corn silage. - Journal of Dairy Science 100: 2625-2636. https://doi.org/10.3168/jds.2016-11862.

[26] Hedemann, M. S., Eskildsen, M., Lærke, H. N., Pedersen, C., Lindberg, J. E., Laurinen, P., Knudsen, K. B. (2006): Intestinal morphology and enzymatic activity in newly weaned pigs fed contrasting fiber concentrations and fiber properties. - Journal Animal Science 84: 1375-1386.

[27] Hu, S., Wang, Y., Wen, X., Wang, L., Jiang, Z., Zheng, C. (2018): Effects of lowmolecular-weight chitosan on the growth performance, intestinal morphology, barrier function, cytokine expression and antioxidant system of weaned piglets. - BMC Veterinary Research 14(1): 215.

[28] Ingvar, B. (2004): Fibre effects on intestinal functions (diarrhea, constipation and irritable bowel syndrome). - Clinical Nutrition Supplements 1: 33-38.

[29] Jarrett, S., Ashworth, C. J. (2018): The role of dietary fibre in pig production, with a particular emphasis on reproduction. - Journal of Animal Science and Biotechnology 9: 59.

[30] Jin, Y. M., Jiang, C., Zhang, X. Q., Shi, L. F., Wang, M. Z. (2018): Effect of dietary Urtica cannabina on the growth performance, apparent digestibility, rumen fermentation and gastrointestinal morphology of growing lambs. - Animal Feed Science and Technology 243: 1-9.

[31] Jiang, J. F., Song, X. M., Huang, X., Zhou, W. D., Wu, J. L., Zhu, Z. G., Zheng, H. C., Jiang, Y. Q. (2012): Effects of alfalfa meal on growth performance and gastrointestinal tract development of growing ducks. - Asian-Australasian Journal of Animal Sciences 25: 1445.

[32] Jørgensen, H., Zhao, X. Q., Eggum, B. O. (1996): The influence of dietary fibre and environmental temoperature on the development of the gastrointestinal tract, digestibility, degree of fermentation in the hind-gut and energy metabolism in pigs. - British Journal of Nutrition 75: 365-378. https://doi.org/10.1079/BJN19960140.

[33] Kick, A. R., Tompkins, M. B., Flowers, W. L., Whisnant, C. S., Almond, G. W. (2012): Effects of stress associated with weaning on the adaptive immune system in pigs. Journal of Animal Science 90: 649-656.

[34] Kleessen, B., Hartmann, L., Blaut, M. (2003): Fructans in the diet cause alterations of intestinal mucosal architecture, released mucins and mucosa-associated bifidobacteria in gnotobiotic rats. - British Journal of Nutrition 89: 597-606.

[35] Lara, E. C., Bragiato, U. C., Rabelo, C. H., Messana, J. D., Reis, R. A. (2018): Inoculation of corn silage with Lactobacillus plantarum and Bacillus subtilis associated with amylolytic enzyme supply at feeding. 1. Feed intake, apparent digestibility, and microbial protein synthesis in wethers. - Animal Feed Science and Technology 243: 2234.

[36] Li, L. L., Yin, F. G., Zhang, B., Peng, H. Z., Li, F. N., Zhu, N. S., Liu, G (2011): Dietary supplementation with Atractylodes Macrophala Koidz polysaccharides ameliorate metabolic status and improve immune function in early-weaned pigs. - Livestock Science 142: 33-41. http://159.226.152.9/handle/343003/4916.

[37] Liu, C., Qu, Y. H., Guo, P. T., Xu, C. C., Ma, Y., Luo, H. L. (2018): Effects of dietary supplementation with alfalfa (Medicago sativa, L.) saponins on lamb growth performance, nutrient digestibility, and plasma parameters. - Animal Feed Science and Technology 236: 98-106.

[38] Metzler, B. U., Mosenthin, R. A. (2008): Review of interactions between dietary fiber and the gastrointestinal microbiota and their consequences on intestinal phosphorus 
metabolism in growing pigs. - Asian-Australasian Journal of Animal Sciences 21: 603615.

[39] Nabizadeh, A. (2012): The effect of inulin on broiler chicken intestinal microflora, gut morphology, and performance. - Journal of Animal and Feed Science 21: 725-734.

[40] National Research Council (1994): Nutrient Requirements of Poultry, Ninth Revised Ed. - National Academy Press, Washington, DC, USA.

[41] National Research Council (2012): Nutrient Requirements of Swine. - National Academies Press, Washington, DC.

[42] Paschke, K., Cumillaf, J. P., Loyola, S., Gebauer, P., Urbina, M., Chimal, M. E., Pascual, C., Rosas, C. (2010): Effect of dissolved oxygen level on respiratory metabolism, nutritional physiology, \& immune condition of southern king crab Lithodes santolla (Molina, 1782) (Decapoda, Lithodidae). - Marine Biology 157: 7.

[43] Pinheiro, V., Outor-Monteiro, D., Mourão, J. L., Cone, J. W., Lourenço, A. L. (2018) Effects of animal type (wild vs. domestic) and diet alfalfa level on intake and digestibility of European adult rabbits (Oryctolagus cuniculus). - Journal of Animal Physiology and Animal Nutrition 102: 460-467.

[44] Ponte, P. I., Mendes, I., Quaresma, M., Aguiar, M. N., Lemos, J. P., Ferreira, L. M., Soares, M. A., Alfaia, C. M., Prates, J. A., Fontes, C. M. (2004): Cholesterol levels and sensory characteristics of meat from broilers consuming moderate to high levels of alfalfa. - Poultry Science 83: 810-814.

[45] Qiu, S. M., Zhou, A. G., Wang, Z. S. (2009): Effects of dietary zinc and protein interaction on performance and blood biochemical parameters of weanling pigs. - China Journal of Animal Nutrition 21: 279-87.

[46] Samanya, M., Yamauch, K. (2002): Histological alterations of intestinal villi in chickens fed dried Bacillus subtilis var. natto. - Comparative Biochemistry and Physiology Part A 133: 95-104.

[47] Sen, S., Makkar, H. P. S., Becke, K. (1998): Alfalfa saponins and their implications in animal nutrition. - Journal of Agricultural and Food Chemistry 46: 131-140.

[48] Varel, V. H. (1987): Activity of fiber degrading microorganisms in the pig large intestine. - Journal of Animal Science 65: 488-496.

[49] Wallig, M. A. (2018): Digestive System. - In: Wallig, M. et al. (eds.) Fundamentals of Toxicologic Pathology (3rd Ed.). Academic Press, Cambridge, MA, pp. 395-442.

[50] Wang, H. F., Yang, W. R., Yang, H. W., Wang, Y., Yang, Z. B., Jiang, S. Z., Zhang, G. G. (2010): Effects of Astragalus membranaceus on growth performance, carcass characteristics, and antioxidant status of broiler chickens. - Acta Agriculturae Scandinavica, Section A, 60: 151-158. https://doi.org/10.1080/09064702.2010.511255.

[51] Wang, H. Y., Jiang, T., Liu, Y. (2015a): Effects of rapeseed on growth performance, nutrient utilization and serum biochemical indexes on Zhedong white geese aged from 7 to 9 weeks. - China Journal of Animal Nutrition 1: 6.

[52] Wang, J., Qin, C., He, T., Qiu, K., Sun, W., Zhang, X., Yin, J. (2018): Alfalfa-containing diets alter luminal microbiota structure and short chain fatty acid sensing in the caecal mucosa of pigs. - Journal of Animal Science and Biotechnology 9: 11.

[53] Wang, L. F., Beltranena, E., Zijlstra, R. T. (2016): Diet nutrient digestibility and growth performance of weaned pigs fed sugar beet pulp. - Animal Feed Science and Technology 211: 145-152.

[54] Wang, M. Z., Liu, Y. F., Wang, W. Q. (2015b): Effects of alfalfa flavonoids on growth performance and serum indexes of sheep. - China Animal Husbandry and Veterinary Medicine 42: 2345-51.

[55] Wellock, I. J., Fortomaris, P. D., Houdijk, J. G. M., Wiseman, J., Kyriazakis, I. (2008): The consequences of non-starch polysaccharide solubility and inclusion level on the health and performance of weaned pigs challenged with enterotoxigenic Escherichia coli. - British Journal of Nutrition 99: 520-530. https://doi.org/10.1017/S0007114507819167. 
[56] Wu, X., Chen, D., Yu, B., Luo, Y., Zheng, P., Mao, X., He, J. (2018): Effect of different dietary non-starch fiber fractions on growth performance, nutrient digestibility, and intestinal development in weaned pigs. - Nutrition 51: 20-28. DOI: 10.1016/j.nut.2018.01.011.

[57] Xia, M. S., Hu, C. H., Xu, Z. R. (2005): Effects of copper bearing montmorillonite on the growth performance, intestinal microflora and morphology of weanling pigs. - Animal Feed Science and Technology 118(3-4): 307-317.

[58] Xie, B. X. (2001): Effects of Flavonoids on Carcass Quality, Lipid Metabolism and Antioxidant Status in Broiler. - Chinese Academy of Agricultural Sciences, Beijing.

[59] Xu, Z. R., Hu, C. H., Xia, M. S., Zhan, X. A., Wang, M. Q. (2003): Effects of dietary fructooligosaccharide on digestive enzyme activities, intestinal microflora and morphology of male broilers. - Poultry Science 82: 648-654.

[60] Yasar, S., Forbes, J. M. (1999): Performance and gastrointestinal response of broiler chickens fed on cereal grain-based foods soaked in water. - British Poultry Science 40: 65-76.

[61] Yu, F., Ge, Y. L., Yang, H. T., Tian, G. H. (2014): Research overview of alfalfa flavonoids. - Food Fermentation Technology 1: 9-13.

[62] Yuan, S. L., Piao, X. S., Li, D. F., Kim, S. W., Lee, H. S., Guo, P. F. (2006): Effects of dietary Astragalus polysaccharide on growth performance and immune function in weaned pigs. - Journal of Animal Science 82: 501-507. https://doi.org/10.1079/ASC200653.

[63] Zhang, A. W., Lee, B. D., Lee, S. K., Lee, K. W., An, G. H., Song, K. B., Lee, C. H. (2005): Effects of yeast (saccharomyces cerevisiae) cell components on growth performance, meat quality, and ileal mucosa development of broiler chicks. - Poultry Science 84: 1015-1021.

[64] Zhou, P. F. (2011): Effects of alfalfa flavonoids excrement on production performance and fat deposition in chicken. - Jiangxi Agricultural University 90(30): 162-1666. 